The Open Mechanical Engineering
Bentham open
CrossMark
Content list available at: www.benthamopen.com/TOMEJ/
DOI: $10.2174 / 1874155 \mathrm{X} 01610010000$

\title{
Retraction Notice: Design and Research of Off-Axis Three-Mirror Space Remote Sensor Structure
}

\author{
Wang Kejun ${ }^{*}, 1,2$ Xuan Ming, Dong Jihong ${ }^{1}$, Chi Chunyan ${ }^{3}$ and Zhang Huanhuan ${ }^{1}$

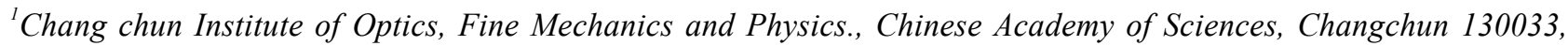 \\ China \\ ${ }^{2}$ University of Chinese Academy of Sciences, Beijing, 100049, China \\ ${ }^{3}$ Jilin Jianzhu University, Changchun 130118, China
}

\section{RETRACTION}

The Publisher and Editor have retracted this article [1] in accordance with good ethical practices. After thorough investigations we believe that the peer review process was compromised. The article was published online on 28-09-2015.

\section{REFERENCE}

[1] W. Kejun, X. Ming, D. Jihong, C. Chunyan, and Z. Huanhuan, "Design and Research of Off-Axis Three-Mirror Space Remote Sensor Structure", Open Mech. Eng. J., vol. 9, pp. 744-751, 2015. 